\title{
SOCIAL DISTANCING OR PHYSICAL DISTANCING? TOWARDS A REAL PARADIGM TO CONTAIN COVID-19
}

\author{
Nnebedum, C.
}

Department of Sociology, Godfrey Okoye University (GOuni), Emene, Enugu State, Nigeria

Corresponding Author Email: nnebedum2003@yahoo.com Phone: +2348136862084

\begin{abstract}
In the time of Corona Virus also known as 'Covid-19', the World Health Organization (WHO) graded the situation as a "pandemic". One of the measures set out in order to contain the disease by all the countries is what they refer to as "social distancing". The term "social distancing" is misleading. What is being actually proposed relates to physical distancing, and deserves to be so described. A more accurate expression "physical distancing," best combined as 'maintaining social closeness while keeping at a physical distance'. In situations like that of Covid-19, social contact is necessary for the psychological-balance of the people. People would need affectionate love and attention from one another through encouragement, sharing of ideas, readiness to help, communications and new contacts. All these are not possible if people are to distance themselves socially. In this paper, we expose the aberrations and inappropriateness of using the term 'social distancing' as a measure in combating Covid-19 and support the use of the term 'physical distancing' instead.
\end{abstract}

Keywords: Covid-19, social distancing, pandemic, physical distancing

LICENSE: This work by Open Journals Nigeria is licensed and published under the Creative Commons Attribution License 4.0 International License, which permits unrestricted use, distribution, and reproduction in any medium, provided this article is duly cited.

COPYRIGHT: The Author(s) completely retain the copyright of this published article.

OPEN ACCESS: The Author(s) approves that this article remains permanently online in the open access (OA) mode.

QA: This Article is published in line with "COPE (Committee on Publication Ethics) and PIE (Publication Integrity \& Ethics)". 


\section{INTRODUCTION}

When the World Health Organization (WHO) observed how wide the Covid-19 which started in Wuhan China on 31st December 2019, as an epidemic, was spreading rapidly to many countries of the world with an unprecedented speed, it declared it a "global health emergency" and graded it on 11th March 2020 as a pandemic situation. It was declared a pandemic by WHO after observing both the alarming levels of spread and severity. When a disease spreads over a country or the whole world, it can be graded as a pandemic. Pandemics are usually capable of spreading rapidly and are infectious diseases. The word pandemic originated from the Greek word 'pandemos' meaning 'affecting all people'. Throughout the history of humanity, there have been a good number of pandemics, for example, tuberculosis, influenza, smallpox, Spanish Flu. Pandemic does not occur only in humans. It can also occur in some important agricultural organisms, for example, in crop plants, livestock and some tree species. Cancer cannot be considered a pandemic disease, even though it affects many people across the world, because it is not infectious.

Covid-19 is a form of disease which belongs to the Severe Acute Respiratory Syndrome's (SARS) family. Vaccines are the most effective measure in the prevention of epidemics and pandemics, but they take time to be developed. In the interim, there are lots of measures put in place by the governments of different countries and WHO to contain the spread of the Covid-19 and one of such is what was initially, and often still, called "social distancing." It is to be understood that the reason for the introduction of 'distancing' as a combative measure is due to the evidence that people, through interaction, may contaminate each other. Such interaction may occur in private or public places. According to Goffman (1963), "public places refer to any regions in a community freely accessible to members of that community; private places refer to soundproof regions where only members or invitees gather" (Goffman, 1963, p. 9). To distance physically is desirable, while to distance socially is not. If it is to be attempted it will have negative effects and will be counter-productive. Social distancing, as a rule, weakens social cohesion. When people disconnect and distance socially, they experience solitary situation and in a situation like Covid-19 pandemic, community engagement, mutual cooperation, inter-personal encouragement and social connections are among the factors needed as synergies to combat the spread of the disease. If we distance physically, we weaken the ability of the virus to be transmitted from one person to another, but if we distance socially, we weaken our human ability to support, encourage, and fight the virus.

\section{AIMS AND OBJECTIVES}

Since the global corona virus pandemic situation has caused havoc to the public and economic lives of the world populace, it is clear that the post pandemic world will look different on many sectors of the society. Economic shock usually leaves a legacy. The public health emergency caused by Covid-19 pandemic has put the world economy to a test, social events and business arrangements witnessed lots of cancellations and re-shaping. Countries locked down and various aspects of the world's social life felt the impact, for example, international trade, aviation, education, hospitality, religion and cultural activities were all put on hold. On the health sector itself, countries reached their limits. Many countries may not be able to emerge from the pandemic with the same vigor as before (Hiscott, et al., 2020). 
It is difficult, at the moment, to predict what will come next. However, any path forward should include using the term "physical distancing" instead of "social distancing." People can physically keep away from each other but, nonetheless, socially connected. Although social distancing is still widely used, this article exposes the wrong message it may be sending across. We are not encouraged to separate socially from family and friends but rather should distance physically with emphasis on keep some meters away from others who are not living in the same household with us.

\section{SOCIAL DISTANCING AS A MEASURE TO CONTAIN COVID-91: A PARADIGMATIC ERROR}

Most often societal changes do bring about some changes in the linguistic usage of words or phrases. That is what we are witnessing with the Covid-19 Pandemic situation. Covid-19 has brought about "new acronyms, and words to express the societal imperatives of imposed isolation and distancing" (Paton, 2020). However, most of those acronyms have been in use for years and some date from 19th century. They were not simply coined because of the Covid-19 Pandemic situation. The novelty about these acronyms is that they gained new usage, and in some cases new meaning, in the face of the Covid-19 Pandemic situation. For instance, the term 'self-isolating' which is used now to refer to self-imposed isolation to avoid either contracting or transmitting the corona virus, was a term used in the 1800s to refer to countries that closed themselves up against political and commercial contacts and interference from the world (Paton, 2020). The term 'social distancing' according to Paton (2020) was not a new term coined because of Covid19: "Social distancing, first used in 1957, was originally an attitude rather than a physical term, referring to an aloofness or deliberate attempt to distance oneself from others socially" (Paton, 2020). Presently, the term 'social distancing' is introduced and understood wrongly to mean keeping a physical distance from each other to avoid infection.

The pandemic situation caused by Covid-19 has resulted in introduction of different measures to contain the disease: covering of mouths and nose, washing and sanitizing of hands and maintaining some distance from each other which is technically, though wrongly, termed "social distancing." The term "social distancing" is applied more when an aberrant behavior is to be avoided. Hence the syntax of the term as far as its meaning is concerned does not equate with its morphology. The term "social distancing" has semblance with the term "social space" in the study of Proxemics which is the study of human use of space and the effects it has on behavior and social interaction (Hall, 1963). In his understanding Hall (1982) presents social distancing as behavior whereby "Intimate visual detail in the face is not perceived, and nobody touches or expects to touch another person unless there is some special effort. Voice level is normal for Americans. There is little change between the far and close phases, and conversations can be overheard at a distance of up to twenty feet." (Hall, 1982, p. 121).

The concept of social distance implies managing distance in our interactions. This is a practice human being learn, with the help of amygdala, as they begin early in life to develop sense of maintaining "personal space." The amygdala is a section of the human brain that helps us to detect fear and prepare for emergencies. It becomes activated when someone or something breaches our secure space. We form memories of acceptable and detestable situations in our surroundings through the help of amygdala.

The unseen impact of social distancing on the emotional wellbeing and mental health of the individual is counter-productive to the desired goal the virologists who coined the term intended. Contextually, social distancing 
implies maintaining at least 2 meters away from people that one does not live in the same household with in order to avoid a possible Covid-19 infection. It is believed that such will help to flatten the curve in the spread of the disease. If the term is to be understood for what it really is in its meaning, it will lead to social isolation. Remaining socially connected has a role to play in a situation like Covid-19 which is unprecedented.

To be socially distancing, one also needs to disconnect. But in the age of technology it becomes difficult to imagine. Exchanging words and glances with each other's presence or non-presence is a common social arrangement. People may be away from each other through quarantine and isolation, so long as they are connecting through different means of communications, e.g, social media (phone and video calls, text messages, Facebook, Twitter, Instagram, Youtube), small talks and sign languages, they are not distancing socially. People get into video conferencing and meeting and some people text or call while watching the same video from their separate locations. The distinctive communication properties of such arrangements are difficult to disentangle. While doing any of these, people are simply keeping close while maintaining distance. That is another form of social connection. Giving the implication of social distancing on the populace, the attention should shift to physical distancing.

\section{PHYSICAL DISTANCING: A BETTER TERMINOLOGY AND ITS EFFICACY IN CONTAINING COVID-} 19

To think of the meaning and implication of "social distancing" as a measure, one has to socially separate oneself from a person or people as if one is avoiding a person or people with aberrant behavior. Thus "physical distancing simplifies the concept with the emphasis on keeping 6 feet away from others" (Fareed, 2020). This is acceptable because it is the gap people give each other that does the trick in helping to reduce the spread and not the connection. Physical presence renders us uniquely accessible and, perhaps, subject to one another. Promulgating and maintaining one of the regulations against the spread of Covid-19 to read - "physical distance", has to do with regulation of the accessibility of face-to-face aspects of our physical interaction with one another for the common good. Goffman (1966) puts it thus: "Perhaps the best explored face-to-face aspect of public order as traditionally defined is what is sometimes called 'public safety'... individuals - especially strangers - are not allowed to ... constitute a source of disease contagion" (Goffman 1966, pp. 22 - 23). Thus, it will be understandable if people are asked to avoid physical contact so as to reduce the spread of the disease but not to avoid social contact.

It is, as matter of fact, important that people stay connected virtually in periods like that to encourage each other and offer assistant as necessary. "Staying in touch with people feeds the human connection we all need to thrive daily, but physical distance is vital to slowing down the spread of the Covid-19 virus" (Fareed, 2020). Here, the main point in focus is avoidance of bodily contact. People can remain socially connected while distancing physically.

Evolutionarily and with the help of amygdala, human beings are wired to give physical distance to people with contagious illnesses. There may be some exceptions to that as in the case of relations. While distancing physically as a survival strategy, other behavioral alternatives like social interaction and communication can be employed to cover and cushion the pains of distancing physically. 


\section{WRONG UNDERSTANDING}

If people are to practice social distancing, as it were, we would witness a situation whereby people would not only keep their distance, but will be afraid of each other even from afar: "... I've seen people not only keeping distant from one another but also seeming afraid. They pass each other on the street or in a store without looking at each other or exchanging greetings" (Banks, 2020). If we are to distance socially there could be a potential stress disorder among some people which may set up some other sicknesses apart from Covid-19 (Banks, 2020). This can be adduced from the experiences of people who have gone solitary confinement which is a form of torture. "The physical and emotional toll it takes over time includes a worsening of mental health issues, an increase in self-injurious behavior and even suicide" (Banks, 2020). When the authorities set "social distancing" as a measure to contain Covidi-19, it could variably be interpreted to mean that they want people to be isolated and recoil to themselves - a sort of being trapped. People may be alive but may not be well and healthy as a result. During the lockdowns people were isolated. Those who contracted the virus are isolated. Those who came in contact with them or may have come in contact with them are asked to self-isolate. Asking them and others who are free to distance socially from one another would result in less social connectedness and less community-based activities which are most needed in such situation (Tannen, 2020). Through social connection, people who are isolated due to physical distancing could be reached out to during a pandemic time.

\section{THE IMPORTANCE OF TERMINOLOGICAL CORRECTION}

To change the terminology from social distancing to physical distancing will help to reduce the confusions described above. It is vital to remain socially connected with each other to keep our humanity alive.

The term "social distancing" has some misleading understanding in terms of implementation if people are to adhere strictly to its meaning (Gale, 2020). In response to the incoherency of the term, the WHO started using the term "physical distancing" instead. Also, on March $20^{\text {th }}$, at the virtual launch event for World Happiness Report 2020, the term "physical distancing", with the objective being to maintain and improve social closeness while maintaining the physical distances required to slow the spread of the virus. Health authorities in Canada officially adopted "physical distancing" in March, as did the Prime Minister on March 29 ${ }^{\text {th }}$, and most national media ever since. What is surprising is that this obvious change has not spread more widely. The purpose of this work is to help spread the preferred terminology (Mae-Jones and Cousins, 2020).

In times of disaster, communities where people fare better are those with strong social connections. In his research, Gale (2020) found out that communities in which fewer residents died in Japan's March 2011 earthquake and tsunami were ones with stronger ties. However, some scholars do not think that it is wise to attempt a change in terminology at the time of pandemic to avoid confusion especially when the term has taken root. "People understand what [social distancing] is... they are adopting it as individuals, and organizations are adopting policies that are rooted in this protective action" (Gale, 2020). However, the confusion envisaged in here can be cleared with proper information to the people why the need for the change is imperative. If people are to become conscious of certain new rules within their own value and belief system, they are to be provided with right information about the reason. According to Rokeach (1973) "Ideally, feedback of such information should be simple and unambiguous, providing 
the person with non-technical, easily understandable data about his own values and attitudes, the relations between them, and how they might reflect upon his self-conception. Moreover, the person's attention must somehow be directed towards contradictions that might exist" (Rokeach, 1973, p. 235). The confusion in term points more to the need to adopt the appropriate term. Social distancing, as practiced by the people, presents a paradoxical aspect of the action: People collaborate mutually (i.e. socially) to maintain some six feet or 2 meters (i.e. physically) away from each other. Thus, the term "social distancing" has a physical requirement. By encouraging social connectedness instead of social distancing, we are encouraging a figurative reframing of physical connection to incorporate an idea of collective connectedness (Oswick et al., 2020).

\section{SOCIAL INTERACTION: THE MORE REASON TO STAY CONNECTED}

We all are involved with one another in one way or the other. Most of our communications occur without our coming into one another's immediate presence. Sometimes when we come in contact, non-verbal communication is called for and we, none the less, engage in communication of a sort. The verbal and non-verbal communications help us to stay together and connected with each other. Our appearances and gestures could convey as much information as objects and symbols can. Objects and symbols that we create and place are embodied expressive signs of whatever we may mean and want to communicate. Asking people to distance socially would amount to discouraging people from keeping connected and encouraging each other at the time of Covid-19 pandemic situation.

People can distance physically and at the same time maintain focused interaction by, for example, staring fixedly at each other and expressing their responses on their faces. People have been practicing a certain kind of physical distancing which is referred to as 'civil inattention' (Goffman, 1963). The courtesy of civil inattention takes special form for two persons who are passing each on the street. They perform the courtesy of eye contact without allowing any recognition and as they get closer, the sides of the street are apportioned automatically; "In any case, we have here what is perhaps the slightest of interpersonal rituals, yet one that constantly regulates the social intercourse of persons in our society" (Goffman, 1963, p. 84). By according each other the space needed through distancing physically but at the same time giving each other focused attention, people imply that they are not afraid of each other and do not wish to avoid each other. This gesture is a form of social interaction. Social interaction is "The interrelated behavior of individuals who influence each other by means of communication" (Schneider, 2006, p. 299). For Hare (1976), interaction that is referred to as 'social' could be by means of verbal or non-verbal communication which individuals use to respond to each other in their daily dealings.

\section{CONCLUSION}

Social distancing has a way of alienating people from each other. To practice social distancing would amount to, among many other actions, people altering their course when they come closer to each other. That is unsettling. It would make recovery from the pandemic, when it is over, very difficult. Although there is an undeniable need for "distancing" to contain the spread of Covid-19, obviously the need for such restrictions does not include people distancing socially from one another but rather physically. Asking people to maintain some meters apart from each other does not, as a matter of semantics, mean they should not socialize with each other. It will be a contradiction of 
meaning when we insist on using the term "social distancing" and at the same time interact with people even if we maintain 2 meters apart. The fundamental disposition we have to interact with each other cannot be annihilated by the new superficial habit of social distancing. Mols (2020) encourages governments and stakeholders to encourage social connectedness during the Covid-19 pandemic because "social identity processes are a key source of human strength, and that leaders who tap into these are best positioned to drive the forms of behavior change required to defeat COVID19" (Mols, 2020). Distancing physically helps to contain the spread of the Covid-19 but maintaining social contact, and interacting likewise will facilitate reintegration and normalization when the pandemic is finally over. 


\section{REFERENCES}

Banks, A. (2020). Social vs. Physical Distancing: Why It Matters. The importance of social connection in the pandemic. Retrieved on 12th April, 2020 from: https:/www.psychologytoday.com/us/blog/wiredlove/202004/social-vs-physical-distancing-why-it-matters.

Fareed, S. (2020). What's the difference between physical distancing and social distancing? Retrieved on 30th May, 2020 from: https://www.geisinger.org/health-and-wellness/wellness-articles/2020/04/08/13/47/socialdistancing-vs-physical-distancing.

Gale, R. (2020). Is 'social distancing' the wrong term? Expert prefers 'physical distancing,' and the WHO agrees. Retrieved on 26th March, 2020 from: https://www.washingtonpost.com/lifestyle/wellness/socialdistancing-coronavirus-physical-distancing/2020/03/25/a4d4b8bc-6ecf-11ea-aa80c2470c6b2034_story.html.

Goffman, E. (1963). Behavior in Public Places. New York: The Free Press.

Hall, E. T. (1963). A System for the Notation of Proxemic Behavior. American Anthropologist. 65 (5): 1003 -1026.

Hall, E.T. (1982). The Hidden Dimension. New York: Anchor books.

Hare, A.R. (1976). Handbook of Small Group Research. (2nd ed.). New York: Free Press.

Hiscott, J., Alexandridi, M., Muscolini, M., Tassone, E., Palermo, E., Soultsioti, M. and Zevini, A. (2020). The Global Impact of the Coronavirus Pandemic. Cytokine and Growth Factor Reviews, 53(2020): 1-9

Mae Jones, A. and Cousins, B. (2020). Covid-19: Health officials recommend 'physical distancing, 'but what is it? Retrieved on 17th October, 2020 from: https://www.ctvnews.ca/health/coronavirus/covid-19-healthofficials-recommend-physical-distancing-but-what-is-it-1.4849541

Mols, F. (2020). Behavior Change Amid Covid: Excerpt from 'Together Apart'. Retrieved on 19th June, 2020 from: https://socialsciencespace.com/2020/06/behavior-change-amid-covid-excerpt-from-together-apart

Oswick, C., Grant, D., and Oswick, R. (2020). Categories, Crossroads, Control, Connectedness, Continuity, and Change: A Metaphorical Exploration of COVID-19. The Journal of Applied Behavioral Science. Retrieved on 19th June, 2020 from: https://doi.org/10.1177/0021886320936257

Paton, B. (2020). Social change and linguistic change: the language of Covid-19. Retrieved on 29th June, 2020 from: https://public.oed.com/blog/the-language-of-covid-19/

Rokeach, M. (1973). The nature of human value. New York: Collier Macmillan Publishers.

Schneider, J. F. (2006). "Interaction" in Outhwaite, W. (ed.) (2006). The Blackwell Dictionary of Modern Social Thought. MA, USA: Blackwell Publishing Ltd.

Tannen, D. (2020). The personal becomes dangerous. Politico Magazine. Retrieved on 19th March, 2020 from: https://www.politico.com/news/magazine/2020/03/19/coronavirus-effect-economy-life-societyanalysiscovid-135579 